\title{
The effect of exercise and complete decongestive therapy on edema volume and shoulder range of motion in patients with breast cancer related lymphedema: A randomized clinical trial
}

\author{
Roghayeh Mokhtarihesari ${ }^{1}$, Roghayeh Poozesh Jadidi ${ }^{1 *}$, Zahra Shaikhi-mobarakeh ${ }^{2}$, Karim Azali Alamdari $^{3}$ \\ 1. Islamic Azad University, Tabriz Branch, Tabriz, Iran \\ 2. Breast Cancer Research Center, Motamed Cancer Institute, ACECR, Tehran, Iran \\ 3. Faculty of Education and Psychology, Azarbaijan Shahid Madani University, Tabriz, Iran
}

Received: 14 September 2020

Accepted for publication: 9 January 2021

[EPub a head of print-20 January 2021]

Payesh: 2021; 20 (1):59-69

\begin{abstract}
Objective (s): Secondary lymphedema is known as a common complication after breast cancer treatment. Exercise is considered as a valuable intervention in these patients. The aim of this study was to investigate the effect of exercise on reducing edema volume and improving shoulder range of motion in breast cancer patients with lymphedema.

Methods: Thirty patients with lymphedema were included in this randomized double-blind study. Fifteen patients were randomly assigned to the exercise plus complete decongestive therapy (exercise + CDT) group and the rest was allocated to the control group (CDT only). In exercise group, patients received a Pilates exercise program with a routine CDT. Variables of edema volume and shoulder range of motion were measured in five different times including before treatment, on 7, 14,21 , and 42-day of the treatment. Repeated measures analysis of variance was used.

Results: The mean age (SD) of patients in the study was 56.3 (6.1) years. Before treatment, there was no significant difference between the two groups in terms of clinical and demographic variables. Although there was no statistically significant difference between the two groups, an improvement in shoulder range of motion and edema volume were observed in two groups over time. Based on the results, the effect of complete decongestive therapy alone and in combination with exercise (Pilates) on edema volume and shoulder range of motion were statistically significant as indicated by within group comparison during the study period $(\mathrm{p}<0.05)$.

Conclusion: The exercise can improve the shoulder range of motion and also can lead to less pain and volume in patients suffering from breast cancer related lymphedema. Although there was no significant difference between the two groups in terms of improvement in shoulder range of motion or edema volume, no adverse effect of Pilates was noticed.
\end{abstract}

Key Words: Exercise (Pilates), Breast cancer, Lymphedema, edema volume, shoulder range of motion.

\footnotetext{
* Corresponding author: Islamic Azad University, Tabriz Branch, Tabriz, Iran

E-mail: poozesh@iaut.ac.ir
} 
نشريه يروهشكده علوم بهداشتى جهاددانشكاهى

\title{
اثر تمرين ورزشى و درمان احتقان زايى تركيبى بر حجم ادم و محدوده حركتى شانه در بيماران مبتلا به سرطان يستان با عارضه لنف ادما: يك مطالعه كار آزمايى بالينى ورديى
}

رقيه مختارى حصارى'، رقيه يوزش جديدى '، زهرا شيخى مباركه ‘ كريم آزالى علمدارى"

1. إنشكاه آزاد اسلامى واحد تبريز، تبريز، ايران

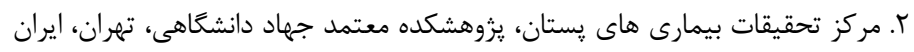

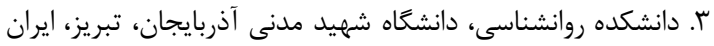

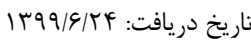

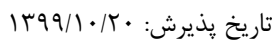

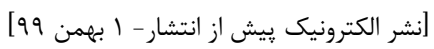

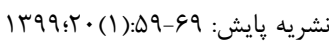

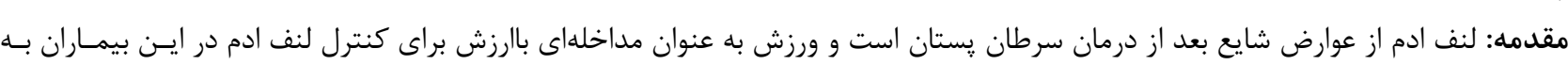

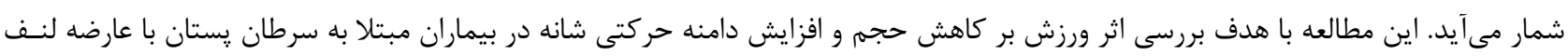

$$
\text { ادم است. }
$$

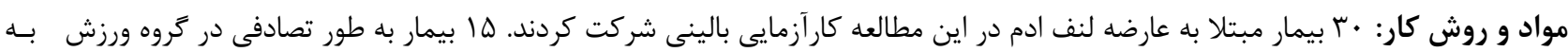

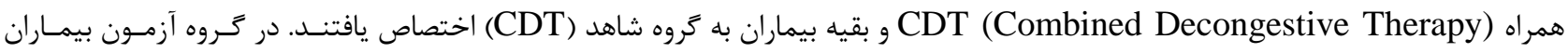

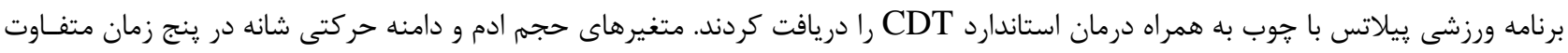

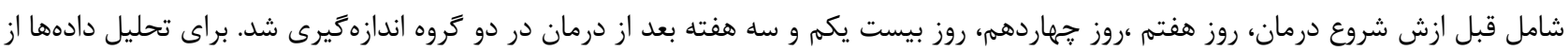

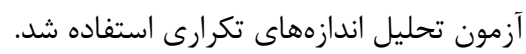

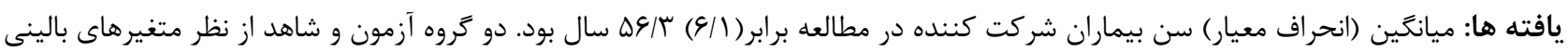

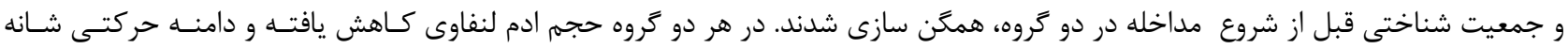

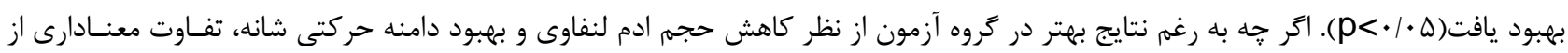
اين نظر بين دو كروه مشاهده نشد.

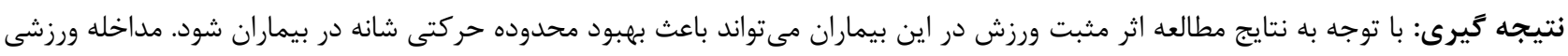

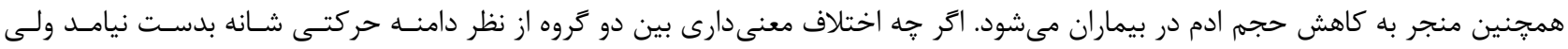

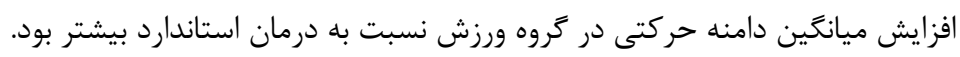
كليدوازه: ورزش بيلاتس، سرطان پستان، لنف ادم، حجم ادم، محدوده حركتى شانه

كد اخلاق: IR.SSRI.REC.1399.766 كدار كد كار آزمايى بالينى:IRCT20200421047158N1 
فرد ابتدا از طريق كنترل به شيوه هدفمند، كنترل جسم خود را بـــ

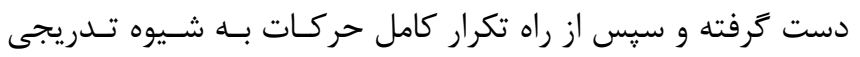

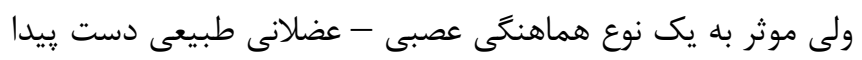

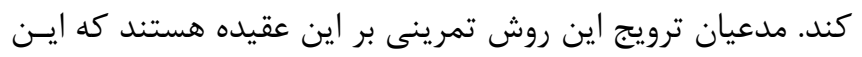

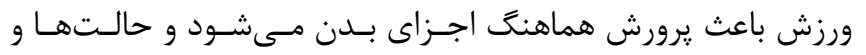

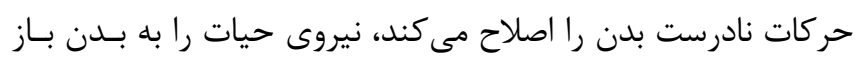

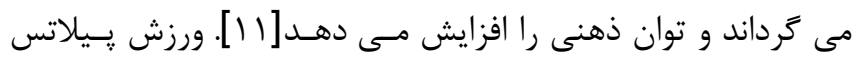

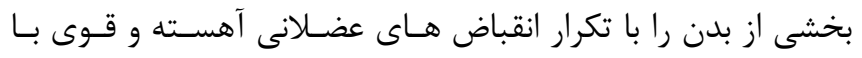

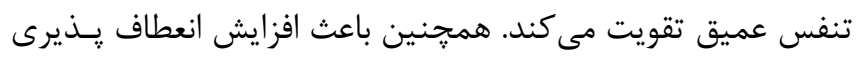

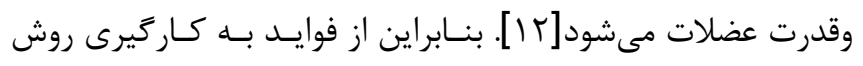

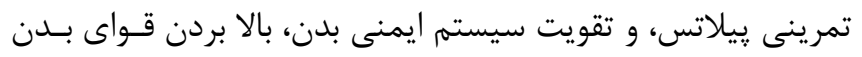

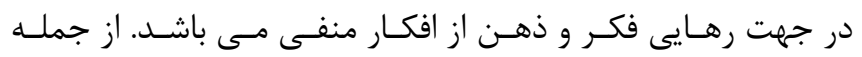

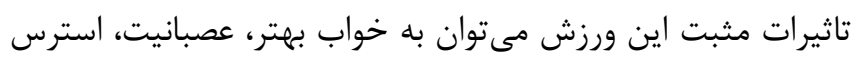

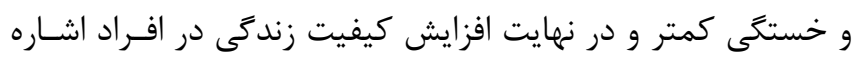

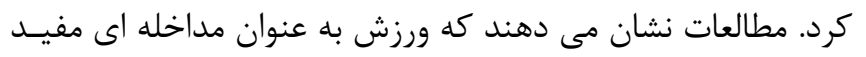

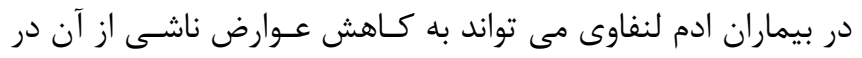

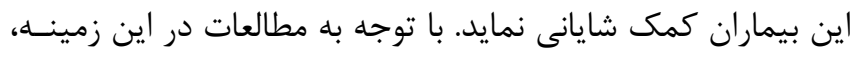

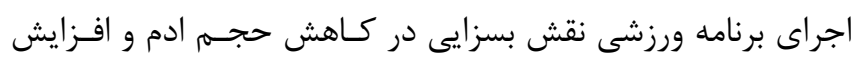

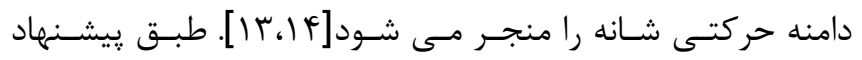

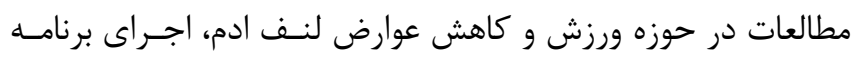

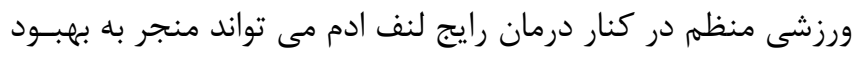

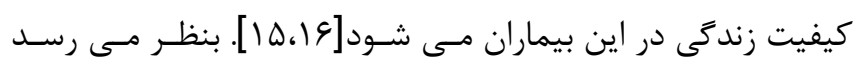

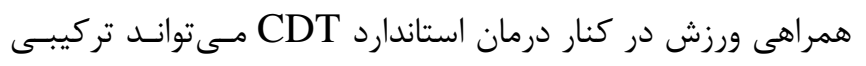

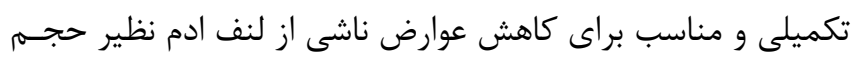

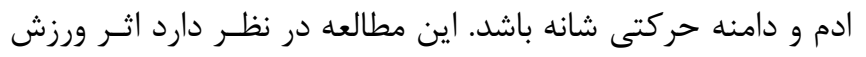

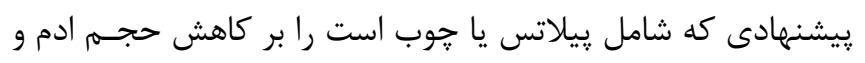

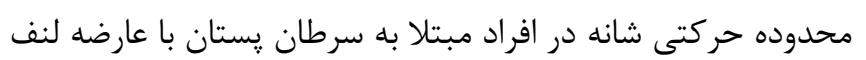

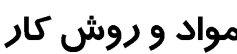

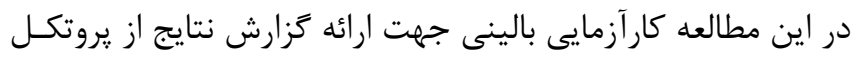

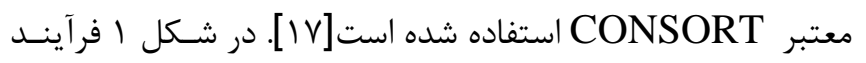

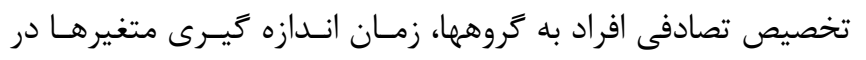
كروههاى آزمون و كروه شاهد نشان داده شده است. اين مطالعه از از

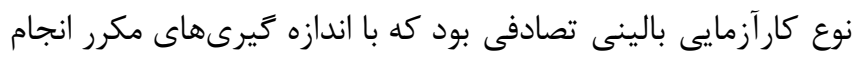

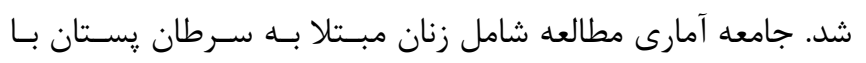

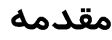

سرطان يستان شـايع تـرين نــوع سـرطان در بـين زنـان در جهـان

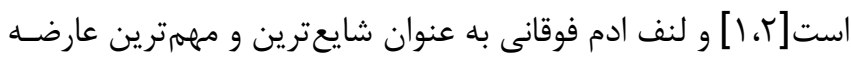

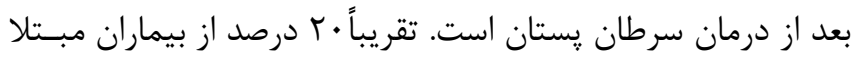

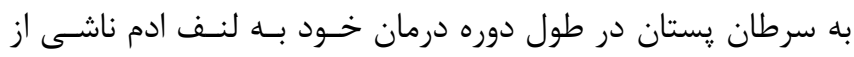

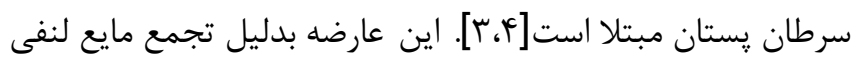

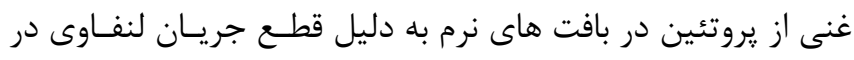

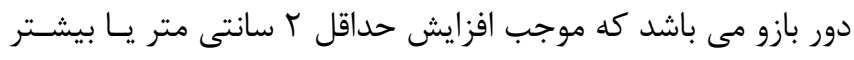

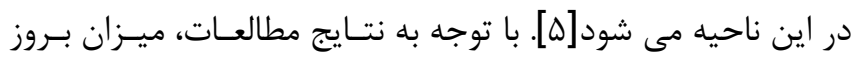

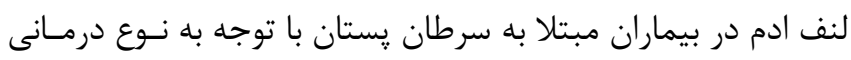

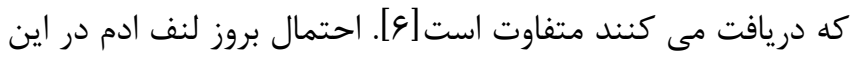

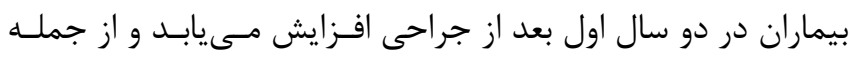

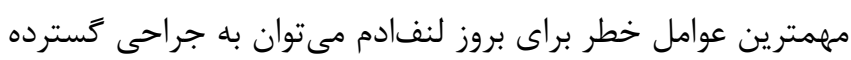

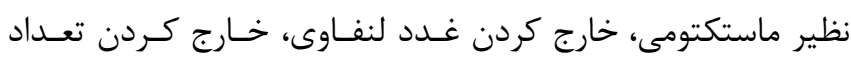

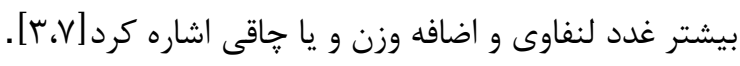

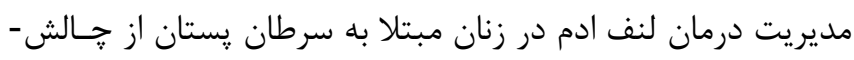

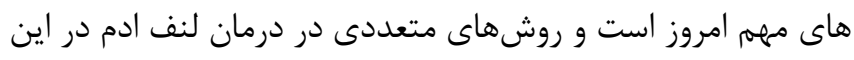

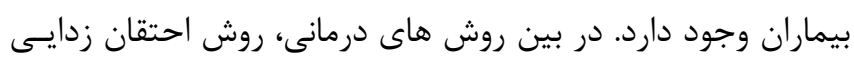
ا تركيبى(combined Decongestive Therapy =CDT مى توان به عنوان درمان موثر و استاندارد در اين بيمـاران نـام بـرد. درمان CDT تركيبى از فنون درمانى شامل تخليه لنفاوى دستى دئى

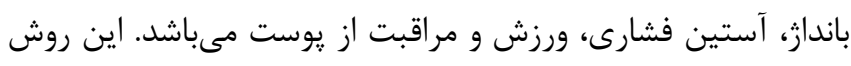

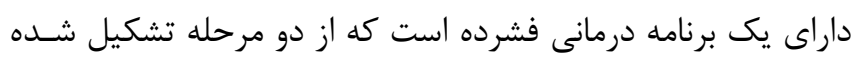

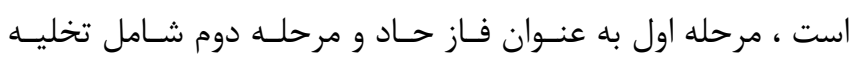

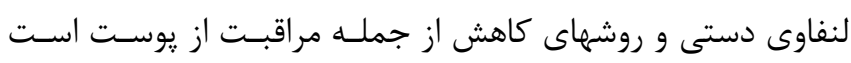

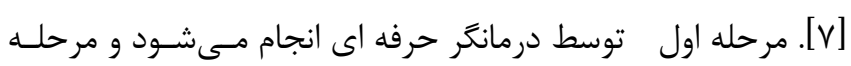
دوم شامل تخليه لنفاوى دستى و مراقبت از يوست است. همجنـ إنـين

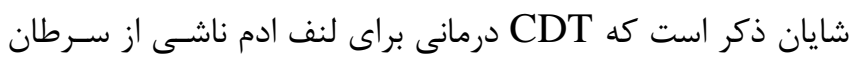

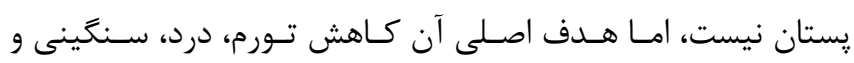

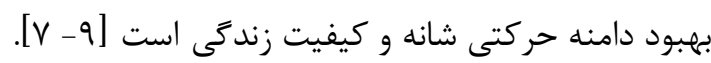

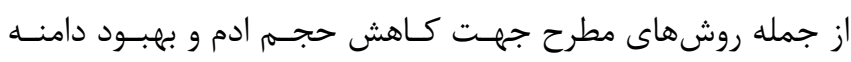

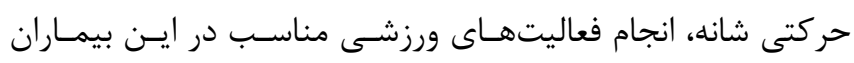

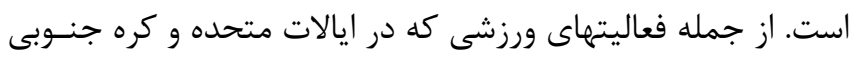

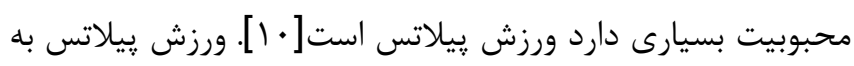

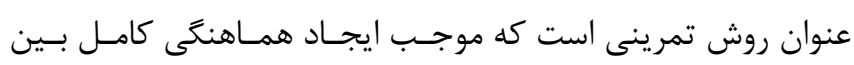
جسم، ذهن و روح مىشود. در اين روش تمرينى، هدف آن است كه كه 
روش جهت تصادفى سازى استفاده شد. از نظر نحوه كور سازى، اين

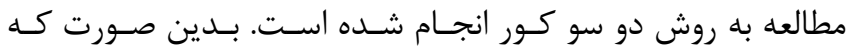

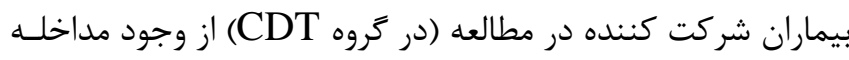

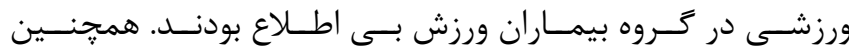
متخصصان انجام لنفوترايى فقط درمان روتين CDT را در بـ بيمـاران

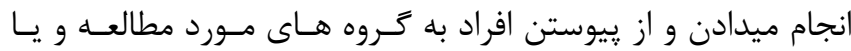
تخصيص برنامه ورزشى به بيمـاران اطلاعى نداشـتند. بيمـاران در

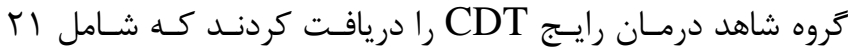

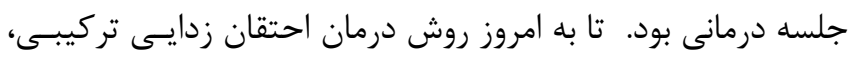

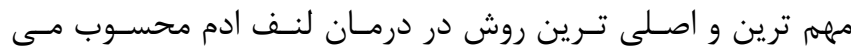

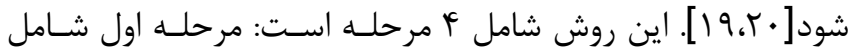

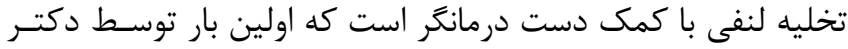
Emil Vodder براى ايجاد فشار مناسب است. مرحله سوم شامل تمرينهاى خاصى

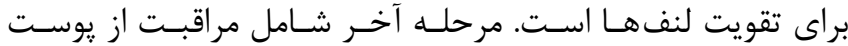

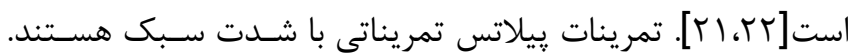

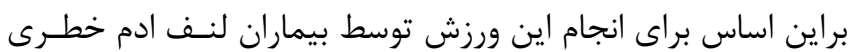

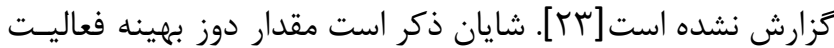

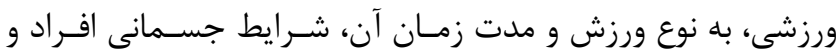
ساير تفاوتهاى فردى بستخى دارد [YF]

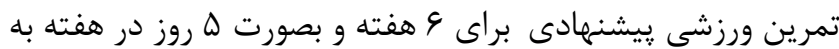

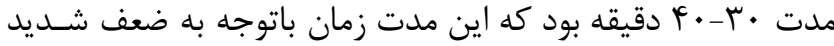

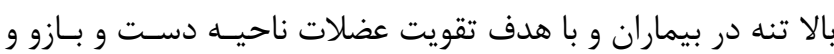

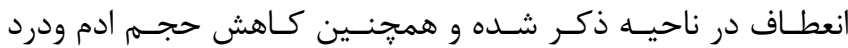
وسنگَينى در سمت مبتلا در نظر گرفته شد[بهـ].

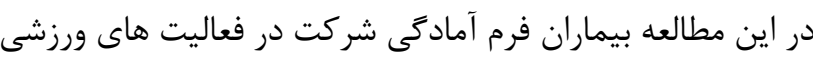
1) (Physical Activity Readiness Questionnaire) تكميل كردند و يزشك لنفولوزيست نيز شركت بيماران را در كـروه

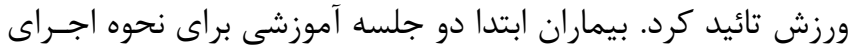
يروتكل ورزش داشتند و سى دى آموزشى در اختيـار بيمـاران قـرار

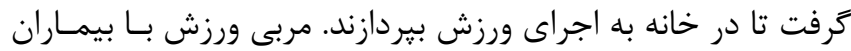

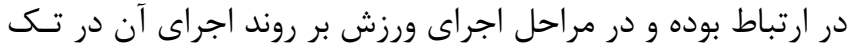

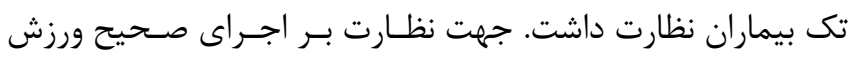

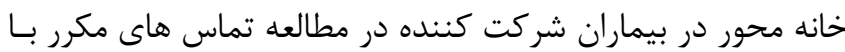
بيماران انجام شد. بطور متوسط تماس ها حداقل يكباردرهفته براى

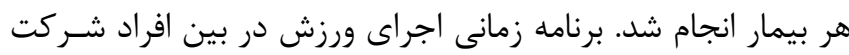

عارضه لنفادم فوقانى بودند كه براى درمان به مطب كلينيك لنـف

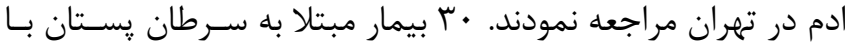

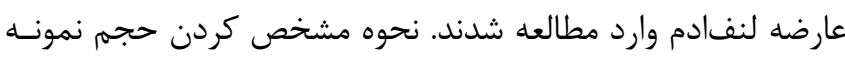

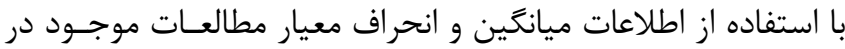

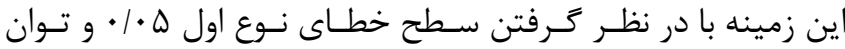

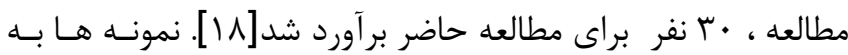

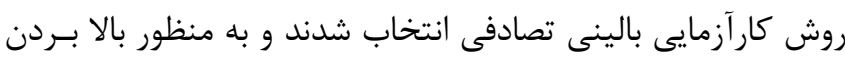

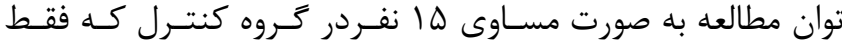

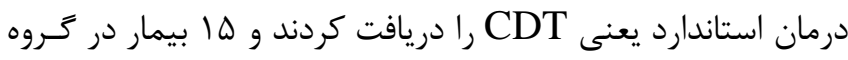

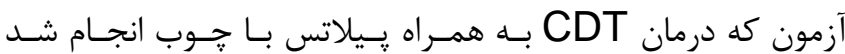

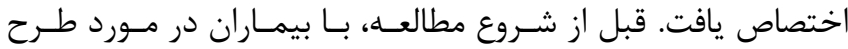

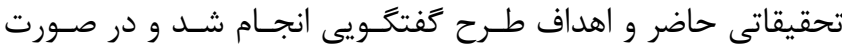

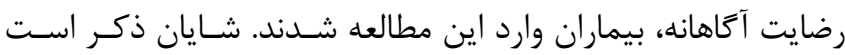
بيماران فرم رضايت شركت در مطالعه را تكميل كردند.

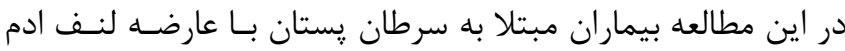

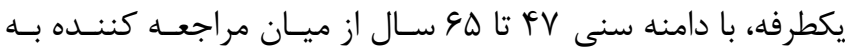

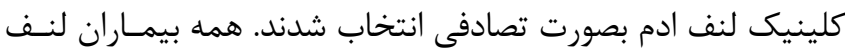
ادم با شدت متوسط تا خفيف در ناحيه دست داشتند كه درجه لنف ادم(شدت لنف ادم) توسط متخصص لنفولوزيست مشخص كرديـد.

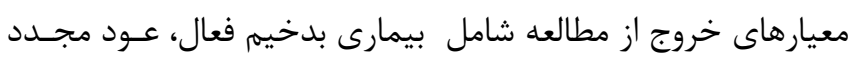

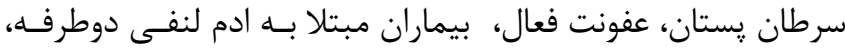
نارسايى وريدى در اندام فوقانى، فعاليت بدنى كمي و ناتوانى در انجـام

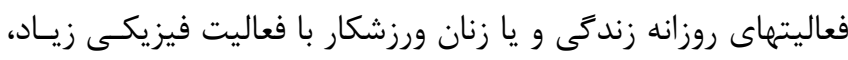

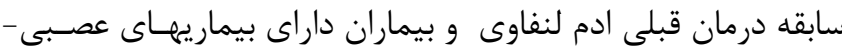
عضلانى در اندام فوقانى مبتلا است. در اين مطالعه از روش تصادفى سازى سـاده اسـتفاده شـد. در ايـنـ

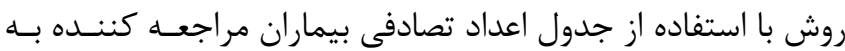

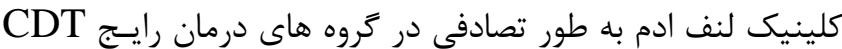

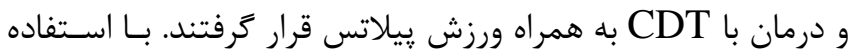

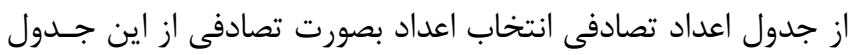

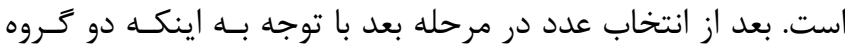

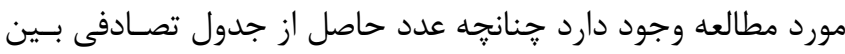

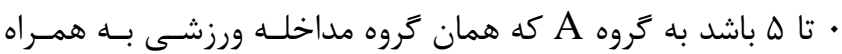

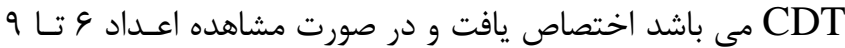

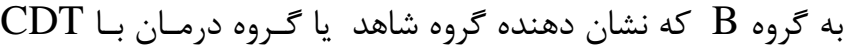

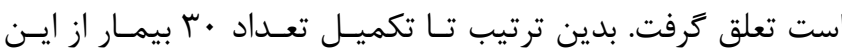




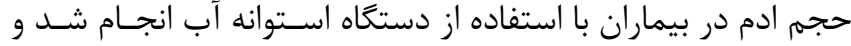

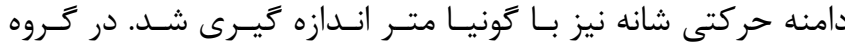

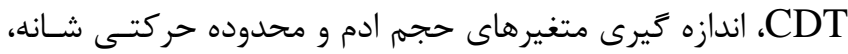
شامل قبل از شروع درمان، جلسه هفتم درمان، جلسه بيست و يكسم إنهم

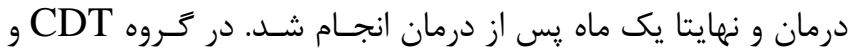

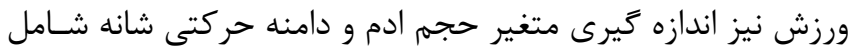

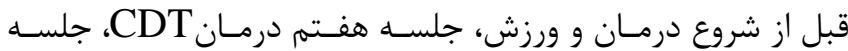

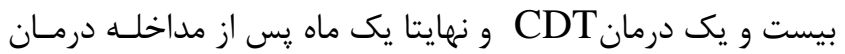

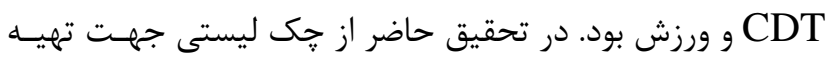
اطلاعات مربوط به مشخصات بالينى و دموكر افيك بيماران استـفاده

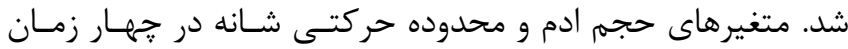

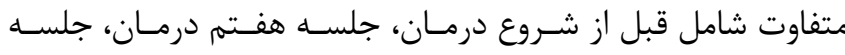

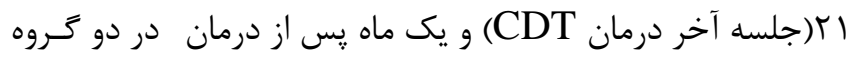

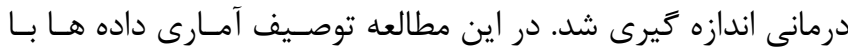

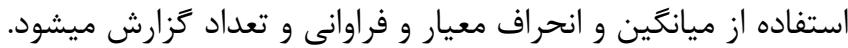

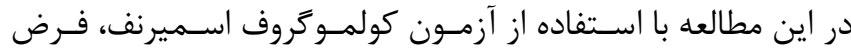
طبيعى بودن متغيرهاى وابسـته حجـم ادم و دامنـه حركتى شـانه

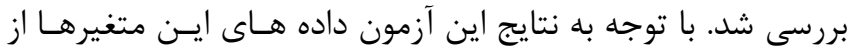

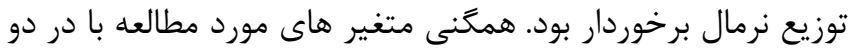

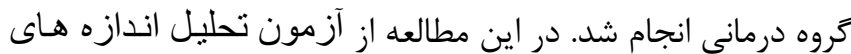
تكر ارى استفاده شد. سطح معنى دارى برابر ه •, • در نظــ كرفتـهـ

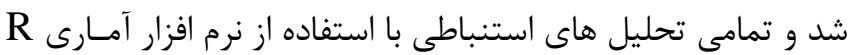

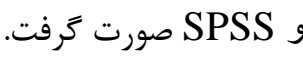

\section{كافتهها}

ميانگين (انحراف معيار) سن بيماران شركت كننده در مطالعه برابـر هQ/ه

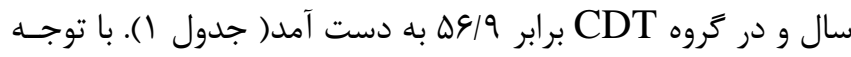

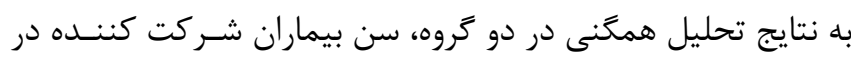

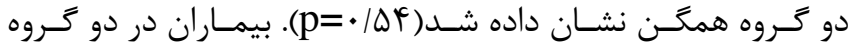

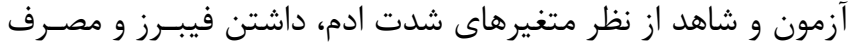

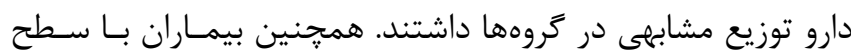

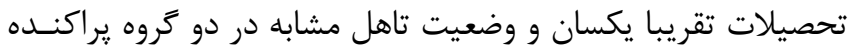
شده اند. بنابراين طبق نتايج تحليل در جدول ال، ا، توزيع بيمـاران در دو كروه درمانى بصورت همخن صورت گرفته است.

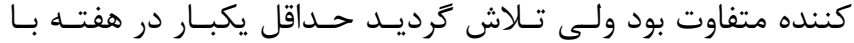

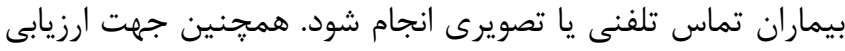

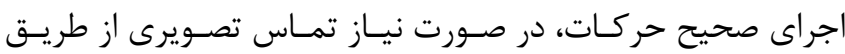

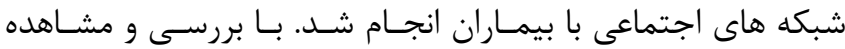
شرايط بيماران در جلسات آموزشى و تمرينى، هدف تمرين و تقويت إندان إندان

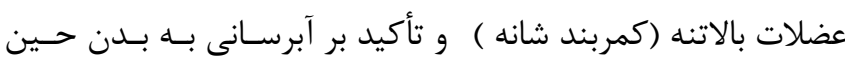

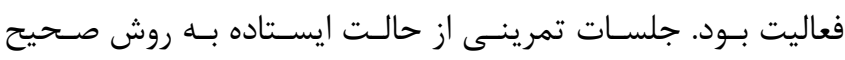

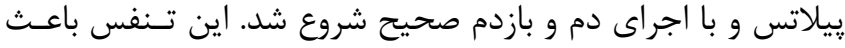

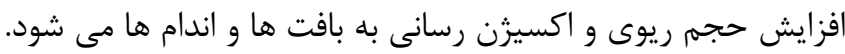

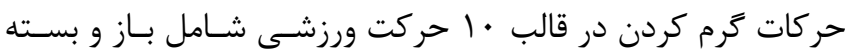

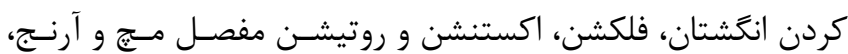
سويينيشن و يرونيشن ساعد، فلكشن دوطرفه مفصل شانه همراه بـاـا تنفس بود. شروع تمرينات با • ا دقيقه كرم كردن با 1 تا • ا تكـرار

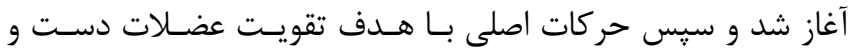
سرشانه با فواصل استراحتى صورت كرفت. در ادامه V حركت تمرين

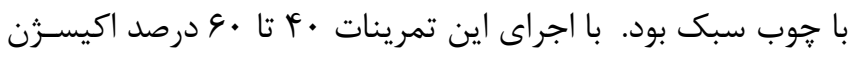

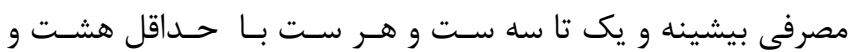

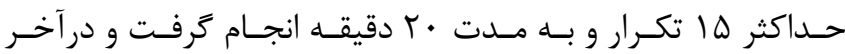

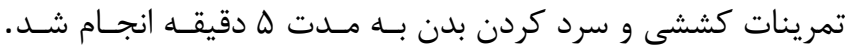

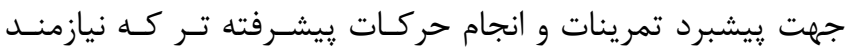

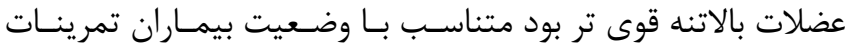

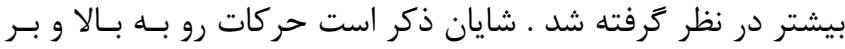

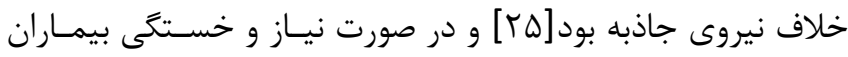
استفاده از صندلى بلامانع بود. در طول تمرين به بيماران توصيه شد شد ندان

$$
\text { از آستين فشارى استفاده شود. }
$$

در اين مطالعه كاهش ادم لنفاوى و همجنين بهببود محدوده حركتى

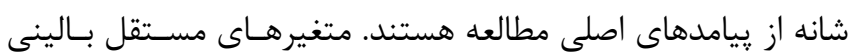

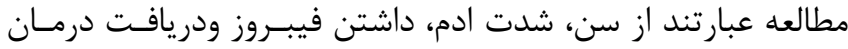

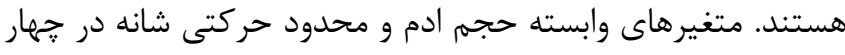

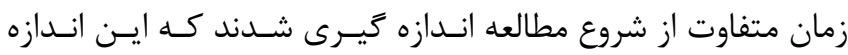

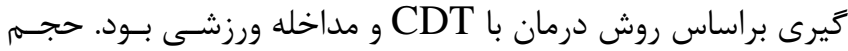

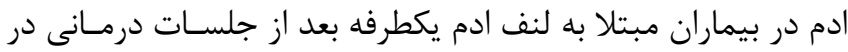

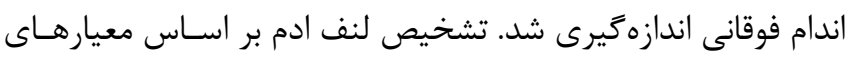
انجمن بين المللى لنفولوزى كذاشته شد. اين معيار شامل بيماران با باريا

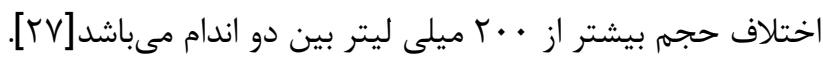


نشريه يثرهشكده علوم بهداشتى جهاددانشعاهى

در گروه آزمون در مقايسه با گروه شاهد، اخـتلاف ميـانگين كـاهش حجم ادم در קيايان مطالعه نسبت به شروع مطالعه بيشتر بود. محدوه

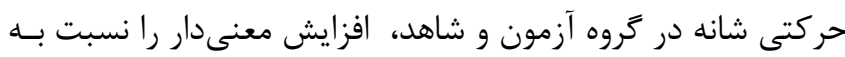

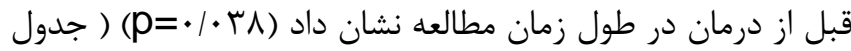

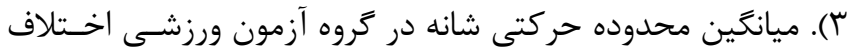

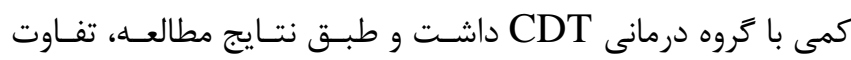

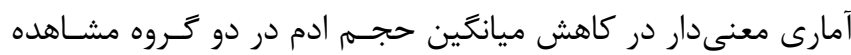

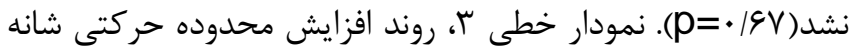
را در طول مطالعه نشان مى دهد. در هر دو گروه رونـد مشـابهلى در

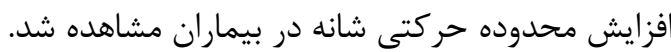

جدول ا، مشخصات دموَرافيك و بالينى بيماران تحت مطالعـه بــهـ

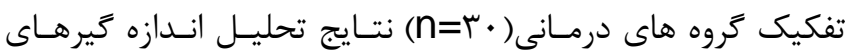
تكرارى در جدول r در دو گَروه CDT و ورزش و گحروه CDT ، كاهش حجم ادم از نظر آمارى اختلاف معنى دار را نسبت به قبـل از از

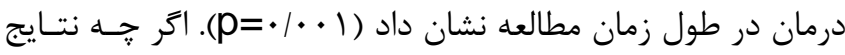

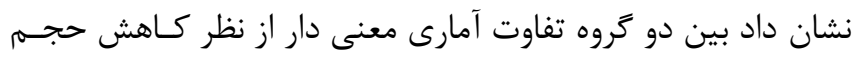

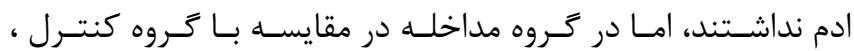

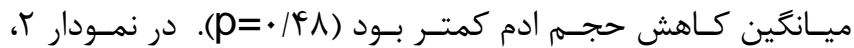
تغييرات حجم ادم لنفاوى را در ينج زمان متفاوت در طول مطالعه با بـان

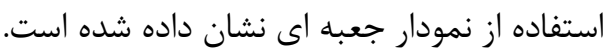

\begin{tabular}{|c|c|c|c|}
\hline P-value & كروه CDT و تمرين ورزشى فرانى & 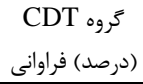 & \\
\hline$\cdot|\Delta|$ & $\Delta \Delta / \Delta \pm \Delta / \cdot F$ & $\Delta \varepsilon / 9 \pm V / 1$ & سن ( انحراف معيارِّ ميانكَين) \\
\hline \multirow[t]{3}{*}{.119} & & & شدت ادم \\
\hline & $\varphi(Y G / V)$ & $\Delta(\Gamma / \Gamma)$ & كمn \\
\hline & $11(V \pi / \Gamma)$ & $1 \cdot(99 / \mathrm{V})$ & متوسط \\
\hline \multirow[t]{3}{*}{.109} & & & داشتن فيبروز \\
\hline & $r(r \cdot)$ & $\Delta(\Gamma / T)$ & دارد \\
\hline & $\mathbb{I r}(\lambda \cdot)$ & $1 \cdot(V G / V)$ & 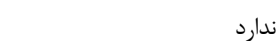 \\
\hline \multirow[t]{3}{*}{$\cdot / 4$} & & & تحت درمان با دارو \\
\hline & $9(9 \cdot)$ & $\Lambda(\Delta T / Y)$ & 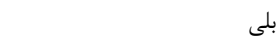 \\
\hline & $\varphi\left(f^{*} \cdot\right)$ & $V(\varphi \in / V)$ & خير \\
\hline \multirow[t]{4}{*}{. } & & & ميزان تحصيلات \\
\hline & $\cdot$ & $1(9,9)$ & بيسواد \\
\hline & $9(9 \cdot)$ & $q\left(f^{*} \cdot\right)$ & دييلم \\
\hline & $q\left(f^{*} \cdot\right)$ & $\Lambda(\Delta \Gamma, r)$ & دانشخاهى \\
\hline \multirow[t]{4}{*}{$\cdot 1 \cdot 1$} & & & وضعيت تاهل \\
\hline & $r(1 T / r)$ & $r(r \cdot)$ & مجرد \\
\hline & $\mid r(\Lambda A / V)$ & $\|(V / / \Gamma)$ & متاهل \\
\hline & $\cdot$ & $I(\varepsilon / V)$ & مطلقه/بيوه \\
\hline
\end{tabular}

جدول ז: اثر كروه و دوره بر كاهش حجم ادم در بيماران مبتلا به لنف ادم دردو كروه شاهد و آزمون

\begin{tabular}{|c|c|c|c|c|c|c|c|}
\hline اثر دوره & 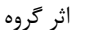 & يكماه يّ از درمان و ورزش & جلسه پِايانى درمان & روز جهاردهم & روز هفتم & قبل از شروع مداخله & \\
\hline P-value & P-value & انحراف معيارثميانگين & انحراف معيار土ميانگين & انحراف معيار ذميانگين & انحراف معيارثميانگين & انحراف معيارثـميانگين & \\
\hline$\cdot 1 \cdot \cdot 1$ & $\cdot / 4 \wedge$ & 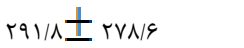 & $r \Delta r / r \pm r \| / r$ & $f \Delta q / 1 \pm_{\Delta q \cdot / \Lambda}$ & $\Delta F \& / \& \pm \Lambda \cdot \Lambda / q$ & $r \varepsilon V / r \pm 11.1 / 9$ & 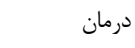 \\
\hline & & $r r \cdot / \Lambda \pm r r q / 1$ & $r \varepsilon q / 1 \pm r r V / V$ & $r \& V / r \pm F V \psi /$. & $r \cdot q / v \pm v \cdot v / v$ & $\Delta T \cdot 19 \pm 111 \cdot / r$ & ورزش و درمان \\
\hline
\end{tabular}

مبتلا به لنف ادم دردو كروه شاهد و آزمون

\begin{tabular}{|c|c|c|c|c|c|c|c|}
\hline & & & \multicolumn{2}{|c|}{ مبتلا به لنف ادم دردو كروه شاهد و ازمون } & \multicolumn{2}{|c|}{ 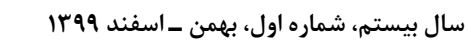 } & 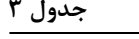 \\
\hline 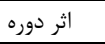 & 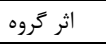 & يكماه يس از درمان و ورزش & جلسه پِايانى درمان & روز جهاردهم & , . & $\ldots, \ldots$ & \\
\hline P-value & P-value & انحراف معيارثميانگين & انحراف معيار_ذميانگين & انحراف معيار_ذميانخين & انحراف معيارثميانگين & انحراف معيار土ميانگين & \\
\hline$\cdot / \cdot r \Lambda$ & $\cdot 19 \mathrm{~V}$ & $1 V \cdot 19 \pm r r / r$ & $r r / r \pm_{199 / r}$ & $r 8 / 9 \pm_{19 \% / r}$ & r I & $k f / r \pm \mid k q / r$ & 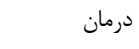 \\
\hline & & $1 \mathrm{~V} 9 / \mathrm{V} \pm_{1 \cdot / 4}$ & $1 \cdot / \Lambda \pm_{1 \vee 9 / 1}$ & $11 / \Lambda \pm_{1 V 9 / 4}$ & $1 \cdot 10 \pm_{1 \mathrm{~V} / 9}$ & $\mid \omega / \Delta \pm_{\mid \varepsilon \%}$. & 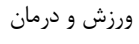 \\
\hline
\end{tabular}




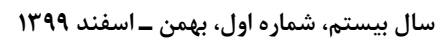

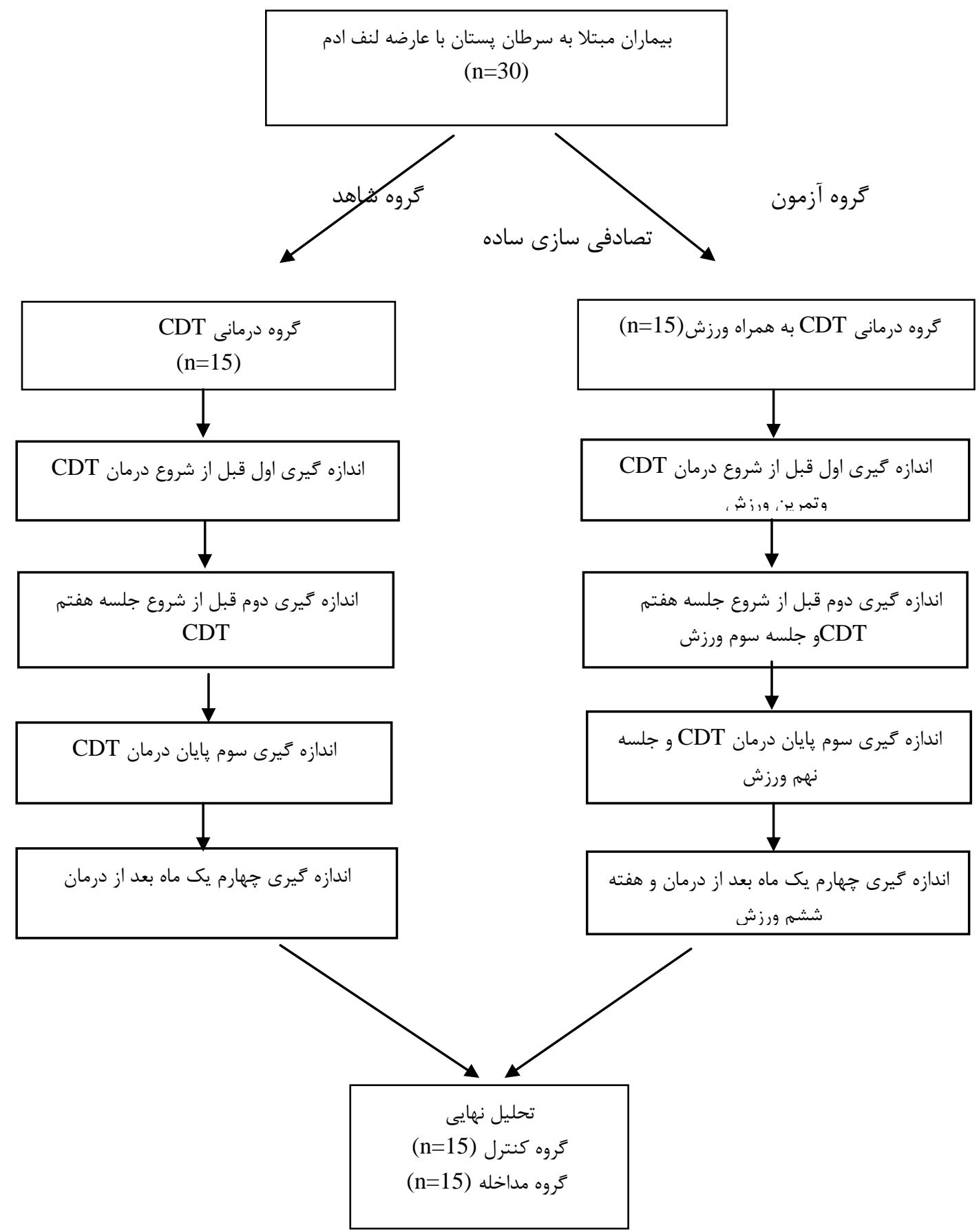

نمودار: يروتكل اجراى فر آيند كار آزمايى بالينى با مداخله ورزش و درمان احتقان زدايى تركيبى در بيماران مبتلا به سرطان يستان با عارضه لنف ادم 
CDT

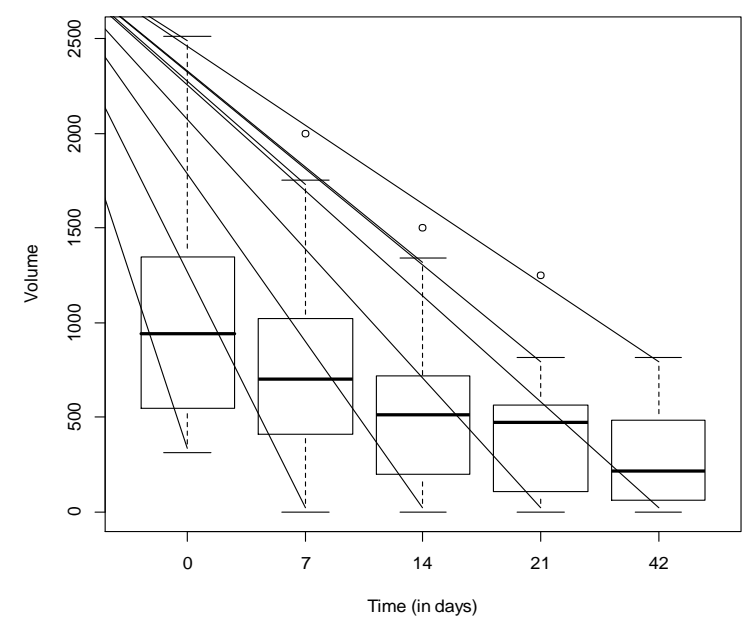

CDT+Exercise

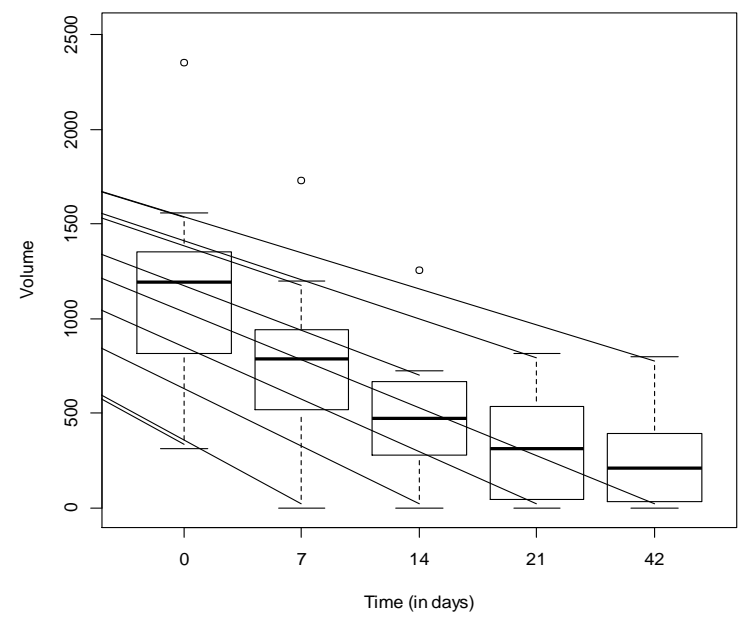

نمودار r، تغييرات حجم ادم لنفاوى در بيماران مبتلا به سرطان يستان با عارضه لنف ادم در دو گروه CDT و CDT با ورزش پييلاتس

مددوه حركتى شدانه

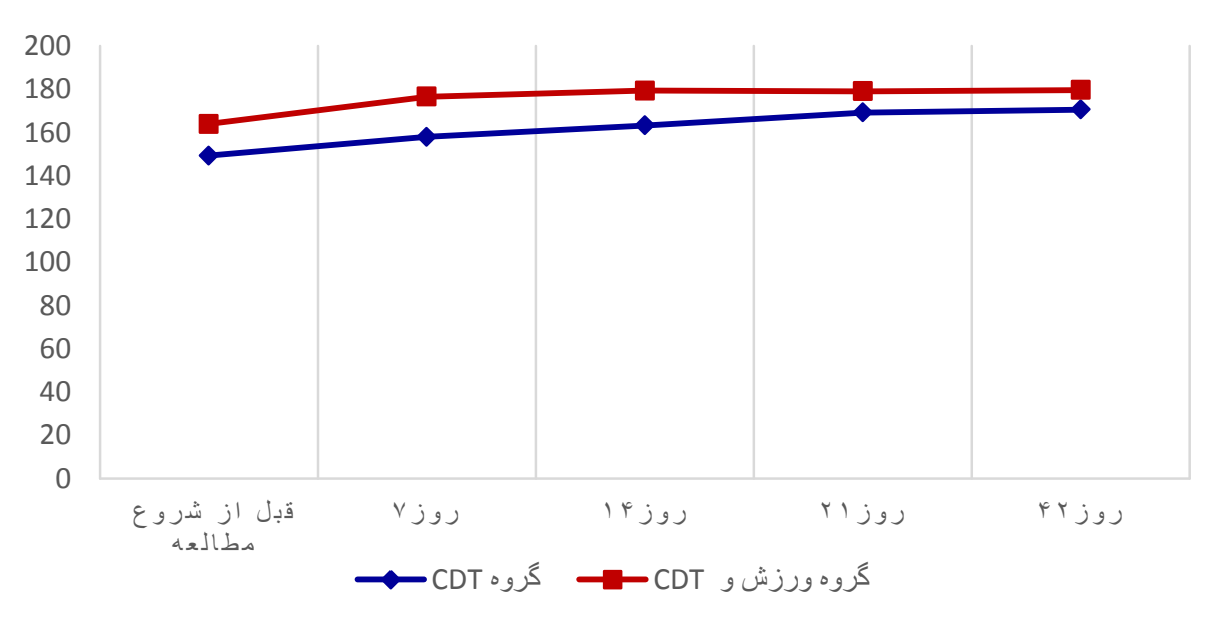

نمودار س: تغييرات ميانكين محدوده حركتى شانه در بيماران مبتلا به سرطان يستان با عارضه لنف ادم در دو كروه CDT و CDT با ورزش ييلاتس
بهبود حجم ادم و افزايش دامنه حركتى شـانه دارنــد. بنـابراين ايـنـ مطالعه با هدف بررسى اثر درمان احتقان زدايى تركيبسى بـهـ همـراه

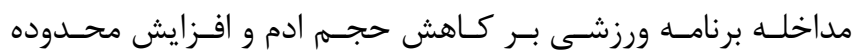

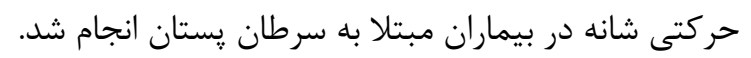

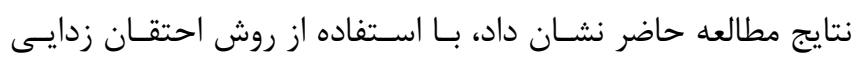
تركيبى، حجم ادم در اغلب بيماران بطور قابل توجهى كاهش داشت

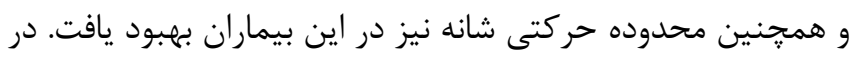

بحث و نتيجه زيرى

لنف ادم به عنوان مهمترين عارضـهـ ثانويسه بعـد از درمـان سـرطان

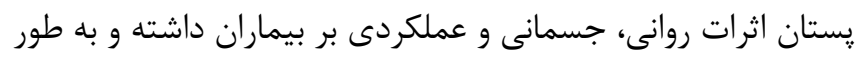

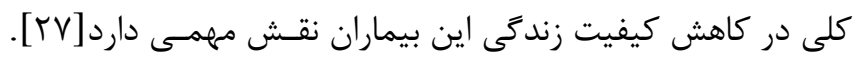

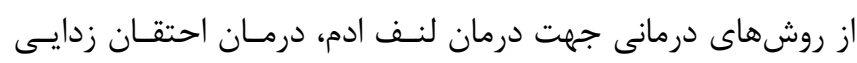

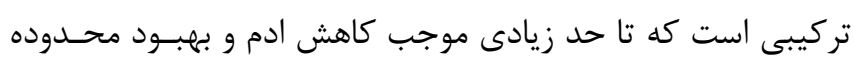

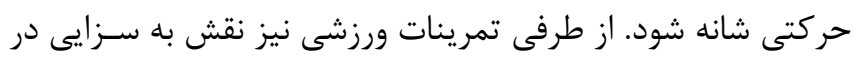


كاهش ورم لنفاوى يا علائم مرتبط با آن را حَزارش نكــده انـد. در

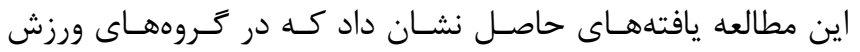
هوازى، ورزش مقاومتى و ورزش تركيبـى حتـى در صـورت داشـتن

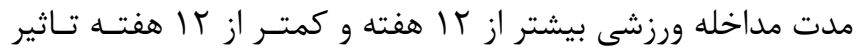

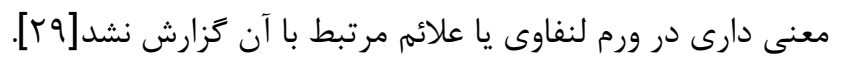
با توجه به ورزش هاى متعددى كه براى بيماران مبـتلا بـه سـرط مركان

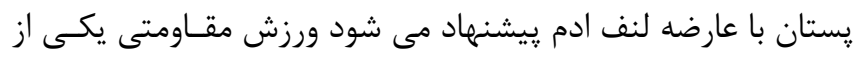

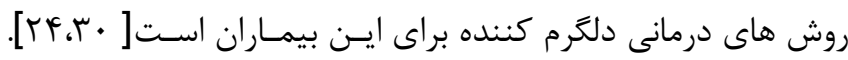

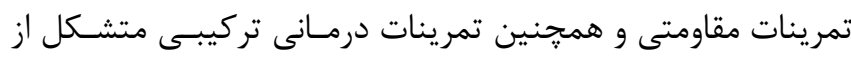

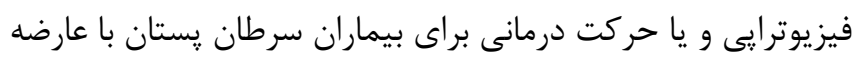

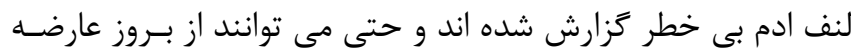

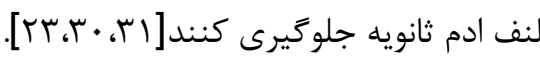

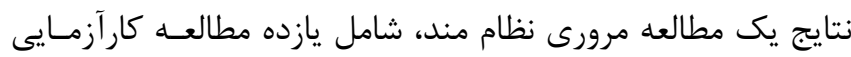

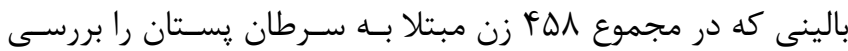

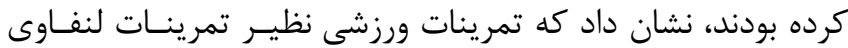

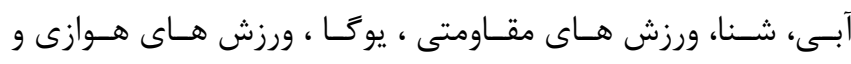

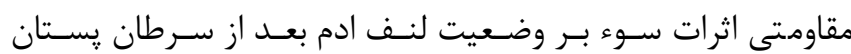

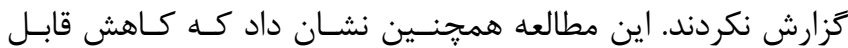
توجهى در حجـهم ادم و بهبـود سـلامت روانسى در بيمـاران مشـاهد

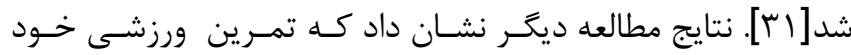
محورى بيماران باعـث كـاهش عــوارض لنـف ادم در ايسن بيمـاران مشاهده نشد. طبق ريشنهاد اين مطالعه، يك برنامه تمرينى منظم و

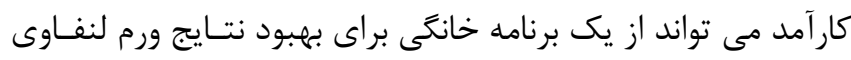

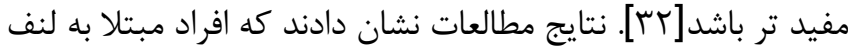
ادم ثانويه مى توانند ورزش منظمم را بدون نكرانى از وخيم تر شـدن

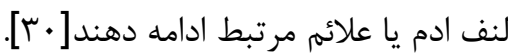

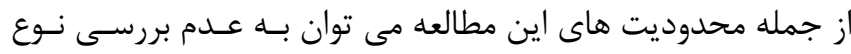
درمانى كه بيماران مبتلا به سرطان يستان در حين درمان لنـف ادم

دريافت كردند اشاره نمود.

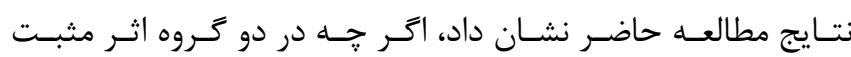

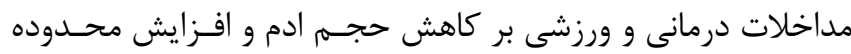

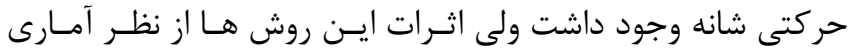

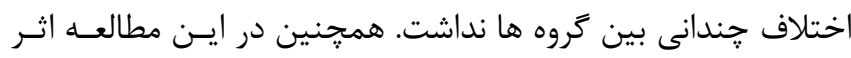

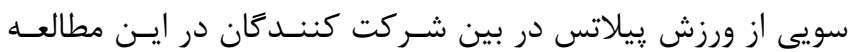
مشاهده نشد و اثر بالينى مثبت بر علايم لنف ادم شامل حجم ادم و

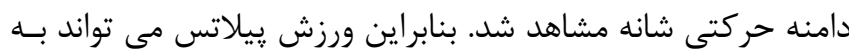

بيمارانى كه علاوه بر درمان CDT مداخله ورزشى را دريافت كـرده بودند نيز افزايش قابل توجهى در كاهش حجــم ادم و بهبـود دامنـهـ

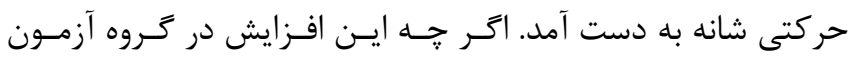
نسبت به گروه درمان استاندارد كمى بيشتر بود ولى تفـاوت آمـارى معنى دار به دست نيامد. مطالعـات زيـادى بـهـ بررسـى اثـر درمـان

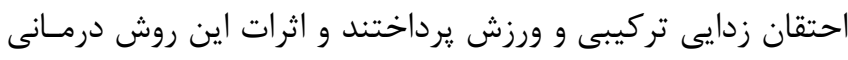

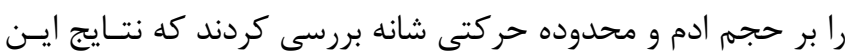
مطالعات در راسـتاى نتــايج مطالعـهـ حاضـر اسـت. بطــور مثــال، در

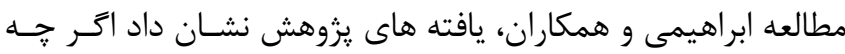

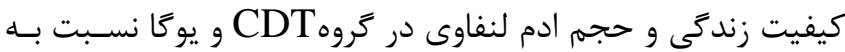
قبل از درمان بهبــود داشـت ولـى تغييـرات نمـره كيفيـت زنـدكى،

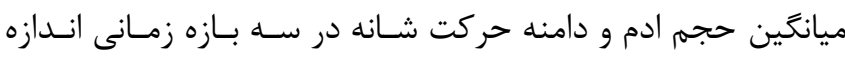

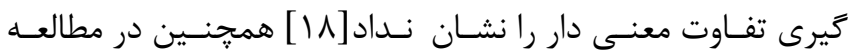

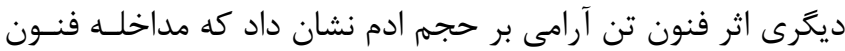
تن آرامى كاهش جشمگيرى در حجم ادم داشت اما اثر اين مداخلـه

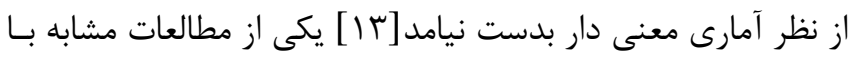

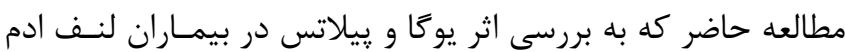

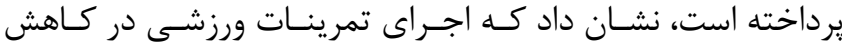
عوارض جانبى ماستكتومى از جمله بهبـود محـدوده حركتى انـدام فوقانى و كاهش حجم ادم موثر بوده اند [ l f نتايج مطالعه Buchan و همكاران نشان داد كه شـركت در ورزش هاى مبتنى بر مقاومت يا هوازى، وضعيت ادم لنفاوى را تغيير نـداد،

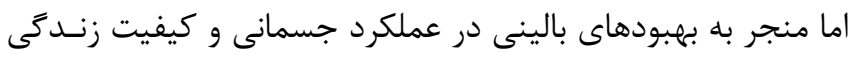

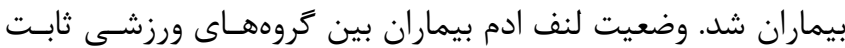
ماند و تفاوت معنى دار مشاهده نشد. اين مطالعه همجنين نشان داد

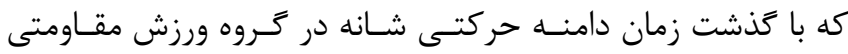
بهبود قابل توجهى نسبت به گروه ورزشى ايروبيـى داشـت. اگرجهـه مداخله ورزشى ايروبيك از نظر آمارى معنى دار به دست نيامـد ولى

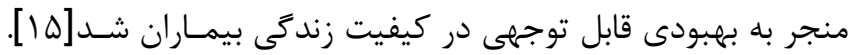

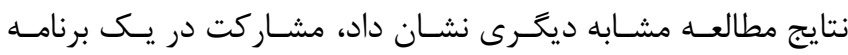
تمرينى فشرده هيج تغييرى در دور بازو يا حجم بازو در زنان مبـتلا

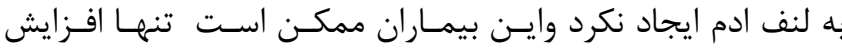

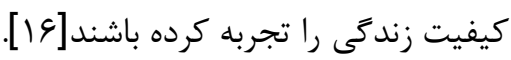

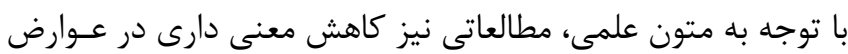

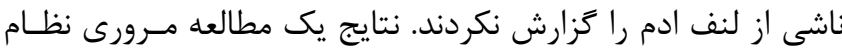

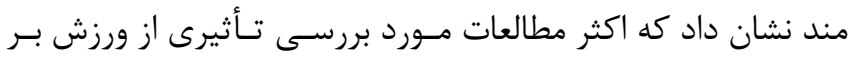




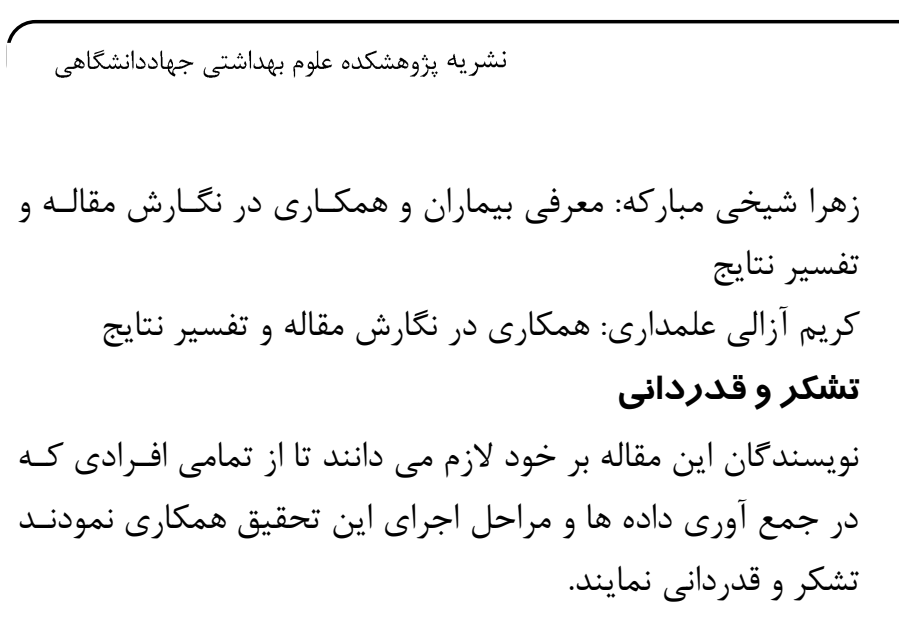

منابع

1. DeSantis C, Ma J, Bryan L, Jemal A .Breast cancer statistics, 2013. A Cancer Journal for Clinicians 2013; 64:52-62

2. Siegel RL, Miller KD, Jemal A. Cancer statistics, 2019. A Cancer Journal for Clinicians 2013; 69:7-34

3. DiSipio T, Rye S, Newman B, Hayes S. Incidence of unilateral arm lymphoedema after breast cancer: a systematic review and meta-analysis. Lancet Oncol 2013;14:505e15

4. Hayes SC, Johansson K, Stout NL, Prosnitz R, Armer JM, Gabram S, Schmitz KH. Upper-body morbidity after breast cancer: incidence and evidence for evaluation, prevention, and management within a prospective surveillance model of care. Cancer 2012; 118: 2237-2249

5. Armer JM, Stewart BR. Post-breast cancer lymphedema: incidence increases from 12 to 30 to 60 months. Lymphology 2010;43:118e27

6. Shah C, Vicini FA. Breast cancer-related arm lymphedema: incidence rates, diagnostic techniques, optimal management and risk reduction strategies. International Journal of Radiation Oncology • Biology - Physics 2011;81:907e14

7. Committee E. The diagnosis and treatment of peripheral lymphedema: 2016 consensus document of the International Society of Lymphology. Lymphology 2016; 49:170-184

8. Hamner JB, Fleming MD. Lymphedema therapy reduces the volume of edema and pain in patients with breast cancer. Annals of Surgical Oncology 2007; 14:1904-1908

9. Mobarakeh Z.S, Mokhtari-Hesari P, LotfiTokaldany $M$ et al. Combined decongestive therapy and reduction of pain and heaviness in patients with breast cancer-related lymphedema. Supportive Care Cancer 2019; 27, 3805-3811

10. Kim ST, Do-Yeon E, Seon-Deok K, Yong-Woon

L. The effect of Pilates training on spinal motion

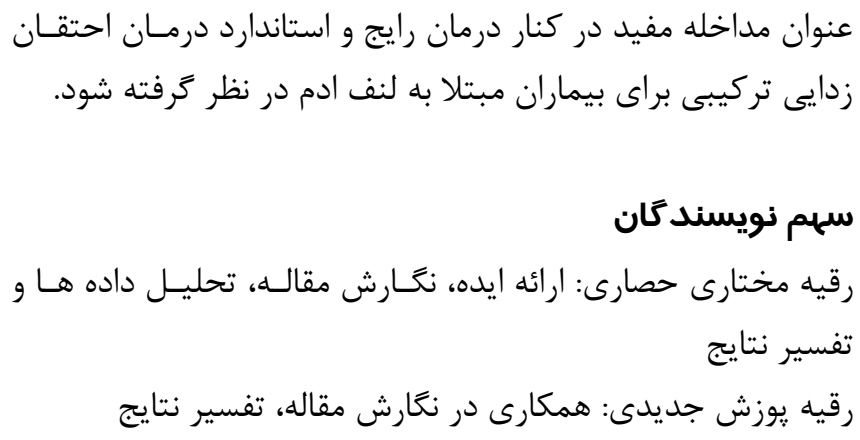

pattern. Journal of Exercise Rehabilitation 2011; 8:6171

11. Banasik J, Williams H, Haberman M, Blank SE, Bendel R. Effect of Iyengar yoga practice on fatigue and diurnal salivary cortisol concentration in breast cancer survivors. Journal of the American Academy of Nurse Practitioners 2011;23:135-142

12. Herrington L, Davies R. The influence of Pilates training on the ability to contract the transverses abdominal muscle in asymptomatic individuals. Journal of Bodywork and Movement Therapies 2015; 9:52-7

13. Mirzakhany N. The effect of relaxation technique associated with complex decongestive therapy (CDT) on edema volume, depression and anxiety in post mastectomy lymphedema. International Journal of Behavioral Development 2015; 8:15-24

14. Ghorbani M, Sokhangouei Y. Three methods of exercise Pilates, yoga and Aktyvrayj on range of motion and upper extremity edema and body image in women with breast cancer after. Journal of Exercise Science and Medicine 2014; 6:189-201

15. Buchan J, Janda M, Box R, Schmitz K, Hayes S. A randomized trial on the effect of exercise mode on breast cancer-related lymphedema. Medicine \& Science in Sports \& Exercise (MSSE) 2016; 48: 18661874

16. McKenzie D. C, Kalda A. L. Effect of upper extremity exercise on secondary lymphedema in breast cancer patients: a pilot study. Journal of clinical oncology 2003; 21: 463-466

17. Equator Network. CONSORT 2010 Statement: updated guidelines for reporting parallel group randomized trials. On Sept, 2020 Available at https://www.equator-network.org/reporting-

guidelines/consort/

18. Ebrahimi M, Haghighat S Khosravi N. The effect of yoga on lymphedema volume, range of motion and 
سال بيسته، شماره اول، بهمن ـاسفند 99\%1

quality of life in breast cancer-related lymphedema. Iranian Quarterly Journal of Breast Disease 2017; 10:7 19. Melam, G. R., Buragadda, S., Alhusaini, A. A., \& Arora, N. Effect of complete decongestive therapy and home program on health-related quality of life in post mastectomy lymphedema patients. BMC women's health 2016; 16: 23

20. Buragadda S, Alhusaini A. A, Melam G. R, \& Arora N. Effect of complete decongestive therapy and a home program for patients with post mastectomy lymphedema. Journal of physical therapy science 2015; 27: 2743-2748

21. Poage E, Singer M, Armer J, Poundall M, Shellabarger MJ. Demystifying lymphedema: development of the lymphedema putting evidence into practice card. Clinical Journal of Oncology Nursing 2008; 12:951-64

22. Foldi M, Foldi E, Kubik S, editors. Textbook of Lymphology: for Physicians and Lymphedema Therapists $3^{\text {th }}$ edition. San Francisco: Urban \& Fischer; 2006

23. Panchik D, Masco S, Zinnikas P, Hillriegel B, Lauder T, Suttmann E, Chinchilli V, McBeth M and Hermann W. Effect of exercise on breast cancer- related lymphedema: What the lymphatic surgeon needs to know. Journal of Reconstructive Microsurgery 2019; 35: 37- 45

24. Gwendolyn A, Thomas M, Lingeng Lu, Herbert $\mathrm{Yu}$, Melinda L. Effect of exercise on metabolic syndrome variables in breast cancer survivors. International Journal of Endocrinology 2013; 1-8

25. Mascherini G, Tosi B, Giannelli C, Grifoni E, Degl'innocenti S, Galanti G. Breast cancer: Effectiveness of a one-year unsupervised exercise program. Journal of Sports Medicine and Physical Fitness 2019; 59:283-289

26. Bloomquist K, Oturai P, Steele ML, Adamsen L, Moller T, et al. Heavy-load lifting: acute response in breast cancer survivors at risk for lymphedema.
Medicine \& Science in Sports \& Exercise 2018; 50:187-95

27. Lee B-B, Andrade M, Antignani P, Boccardo F, Bunke N, Campisi C, et al. Diagnosis and treatment of primary lymphedema. Consensus document of the International Union of Phlebology (IUP)-2013. Int Angiol. 2013;32:541-74

28. Hasenoehrl T, Keilani M, Palma S, Crevenna R. Resistance exercise and breast cancer related lymphedema-a systematic review update. Disability and Rehabilitation 2020; 42: 26-35

29. Singh B, Disipio T, Peake J, \& Hayes S. C. Systematic review and meta-analysis of the effects of exercise for those with cancer-related lymphedema. Archives of Physical Medicine and Rehabilitation 2016; 97: 302-315

30. Bicego D, Brown K, Ruddick M, et al. Exercise for women with or at risk for breast cancer-related lymphedema. Physical Therapy 2006; 86:1398 -1405

31. Schmitz K.H, Troxel A.B, Dean L.T, DeMichele A, Brown J.C, Sturgeon K, Denlinger C. Effect of home-based exercise and weight loss programs on breast cancer-related lymphedema outcomes among overweight breast cancer survivors: The WISER Survivor randomized clinical trial. Jama Oncology 2019; 5: 1605-1613

32. Baumann F.T, Reike A, Hallek M, Wiskemann J, Reimer, V. Does exercise have a preventive effect on secondary lymphedema in breast cancer patients following local treatment-a systematic review. Breast Care 2018; 13: 380-385

33. Wanchai A, Armer J.M. Effects of weight-lifting or resistance exercise on breast cancer-related lymphedema: a systematic review. International Journal of Nursing Sciences 2019; 6: 92-98 